\title{
The Prp18 protein stabilizes the interaction of both exons with the U5 snRNA during the second step of pre-mRNA splicing
}

\author{
Luciana B. Crotti, Dagmar Bačíková, and David S. Horowitz ${ }^{1}$ \\ Department of Biochemistry and Molecular Biology, Uniformed Services University of the Health Sciences, \\ Bethesda, Maryland 20814, USA
}

Interaction of the ends of the exons with loop 1 of the U5 snRNA aligns the exons for ligation in the second step of pre-mRNA splicing. To study the effect of Prp18 on the exons' interactions, we analyzed the splicing of pre-mRNAs with random sequences in the exon bases at the splice junctions. The exon mutations had large effects on splicing in yeast with a Prp18 protein lacking its most conserved region, but not in wild-type yeast. Analysis of splicing kinetics demonstrated that only the second step was affected in vivo and in vitro, showing that Prp18-and specifically its conserved region-plays a key role in stabilizing the interaction of the exons with the spliceosome at the time of exon joining. Superior exon sequences defined by the prp18 results accelerated the second step of splicing by wild-type spliceosomes with inefficient AT-AC pre-mRNAs, implying that normal exon interactions follow the rules we discerned for prp18 splicing. Our results show that As are preferred at the ends of both exons and support a revised model of the interactions of the exons with U5 in which the exons are arranged in a continuous double helix that facilitates the second reaction.

[Keywords: pre-mRNA splicing; U5 snRNA; Prp18; spliceosome]

Supplemental material is available at http://www.genesdev.org.

Received February 5, 2007; revised version accepted March 19, 2007.

Pre-mRNA is spliced in two sequential transesterification reactions within the spliceosome (for review, see Will and Lührmann 2006). The active spliceosome is composed of the U2, U5, and U6 snRNPs together with a dynamic cast of proteins. The U2 and U6 snRNAs form the catalytic core of the spliceosome (for review, see Valadkhan 2005), while the U5 snRNP holds the substrate RNA (Newman and Norman 1991, 1992). The interactions of U5 with the splicing intermediates that position the exons for joining during the second step are the focus of this study.

The second step of splicing can be divided into stages based on the protein and ATP requirements at each stage. After the first transesterification reaction, the DExH-box RNA helicase Prp16 catalyzes an ATP-dependent rearrangement of the spliceosome (Schwer and Guthrie 1992). Prp17 is involved at this stage as well (Jones et al. 1995). Slu7, Prp18, and Prp22 bind to the rearranged spliceosome and facilitate the ATP-independent transesterification reaction that produces the

${ }^{1}$ Corresponding author.

E-MAIL dhorowitz@usuhs.mil; FAX (301) 295-3512.

Article is online at http://www.genesdev.org/cgi/doi/10.1101/gad.1538207.
mRNA (Horowitz and Abelson 1993a; Jones et al. 1995; Schwer and Gross 1998; James et al. 2002). Following exon ligation, Prp22, another DExH family member, catalyzes an ATP-dependent conformational change that releases the mRNA (Company et al. 1991). If the second transesterification is slow, then the Prp22-catalyzed rearrangement may precede the ligation of the exons, allowing proofreading of poor substrates (Mayas et al. 2006). The Prp8 protein, which is required for the first step, also functions in the second step (for review, see Grainger and Beggs 2005).

Prp18 is involved only in the second step of splicing and is associated with the U5 snRNP (Horowitz and Abelson 1993a,b). The functional domain of Prp18 is composed of five tightly packed $\alpha$-helices, the last two of which are connected by a 36-amino-acid flexible loop (Jiang et al. 2000). This loop includes a nearly invariant stretch of 25 amino acids that is the most conserved region in Prp18. The loop can be deleted without affecting the folding of the rest of Prp18, and this mutant Prp 18 protein, called Prp $18 \Delta$ CR /deletion of the conserved region), retains considerable function (Bačíková and Horowitz 2002). Prp18 interacts with Slu7, which binds to the face of Prp18 opposite the conserved loop (Zhang and Schwer 1997; Bačíková and Horowitz 2002). 
This interaction is necessary for both proteins to bind stably to the spliceosome (James et al. 2002). Prp18 $\Delta$ CR, a focus of this study, appears to bind normally to the spliceosome and to lack a function needed during the second step.

The U5 snRNA plays a central role in the second step of splicing in which it aligns the exons for joining (Newman and Norman 1992; O'Keefe et al. 1996). All U5 snRNAs studied have the invariant 9-nucleotide (nt) sequence $5^{\prime}-\mathrm{G}_{1} \mathrm{C}_{2} \mathrm{C}_{3} \mathrm{U}_{4} \mathrm{U}_{5} \mathrm{U}_{6} \mathrm{U}_{7} \mathrm{~A}_{8} \mathrm{C}_{9}-3^{\prime}$ within an $11-\mathrm{nt}$ loop called loop 1 (Frank et al. 1994). Loop 1 interacts with bases at the ends of the exons, tethering them to the spliceosome. The bases at the $3^{\prime}$ end of exon 1 interact with bases $\mathrm{U}_{4} \mathrm{U}_{5} \mathrm{U}_{6}$ in loop 1 , and the bases at the $5^{\prime}$ end of exon2 interact with $\mathrm{C}_{3}$ and $\mathrm{U}_{4}$ (Newman and Norman 1991, 1992). The exon bases that interact with loop 1 are not conserved (Long et al. 1997; Lopez and Séraphin 1999; Spingola et al. 1999), and the basis for this interaction is not well understood. Genetic experiments show that the bases in loop 1 can base-pair with the pre-mRNA or intermediates and that this pairing affects both splice site selection and splicing efficiency (Newman and Norman 1991, 1992; Cortes et al. 1993). Interaction of exon 1 with loop 1 is established before the first step of splicing and persists through the second step, while the interaction with exon2 is not detected until the second step (Sontheimer and Steitz 1993; Newman et al. 1995; McGrail et al. 2006). In yeast extracts, loop 1 is required only for the second step (O'Keefe et al. 1996) although it can affect $5^{\prime}$ splice site choice (Newman and Norman 1991).

Proteins are likely to be important in stabilizing the interaction of U5 with the substrate RNAs. Biochemical experiments have strongly implicated Prp 8 in the process. Prp8, a component of the U5 snRNP, can be crosslinked to loop 1 in free U5 snRNP as well as to the ends of both exons during splicing with kinetics that parallel those of U5 snRNA cross-linking (Teigelkamp et al. 1995; Grainger and Beggs 2005; Turner et al. 2006). Genetic experiments show a close connection between Prp18 and loop 1 of U5. The U5 loop 1 mutations snr7$U 4 A$ and snr7-A8C suppress the growth and splicing phenotypes of prp18 $\triangle C R$ alleles but not of prp18 mutations outside of the conserved region (Bačíková and Horowitz 2005).

We sought to determine directly whether Prp18 stabilizes the interactions of the splicing intermediates with loop 1 of U5. We found that the exonic bases near the splice junctions had a large effect on the second step of splicing in prp18 $\triangle C R$ yeast, showing that the conserved region of Prp18 is important for stabilizing the interaction of the exon ends with U5. Exon sequences affected the inefficient splicing of AT-AC pre-mRNAs by wildtype spliceosomes in the same way that we found in prp18 $\mathrm{CR}$ spliceosomes, indicating that normal exon interactions with loop 1 follow the rules we found for prp18 $\mathrm{CR}$ splicing. Our results lead to a revised model of the interactions of the U5 snRNA with the exons that provides insight into the chemistry of the second reaction.

\section{Results}

\section{Screening of exon mutants}

To determine directly whether Prp18 affects the interaction of loop 1 of U5 with the splicing intermediates, we studied pre-mRNAs in which the exonic bases that interact with loop 1 were mutated. We hypothesized that substrates that could base-pair more strongly with loop 1 would splice better in prp18 $\triangle C R$ yeast, and we expected little effect in wild-type yeast because there is limited conservation of exon bases at the junctions (Long et al. 1997; Lopez and Séraphin 1999; Spingola et al. 1999). We used the ACT1-CUP1 system in which copper resistance reports the efficiency of splicing of the ACT1-CUP1 premRNA (Lesser and Guthrie 1993). We constructed ACT1-CUP1 libraries in which either the four bases at the $3^{\prime}$ end of exon 1 or the three bases at the $5^{\prime}$ end of exon2, or both, were randomized (Fig. 1A). The sequence of the wild-type ACT1 exons is TCTG|AGG, where we write the sequences of the exon ends as exon1/exon2, showing the seven bases that we randomized. The libraries were screened by replica plating in indicator yeast that had the mutant allele prp $18 \Delta C R$ that encodes a Prp18 protein lacking its conserved region or in wildtype indicator yeast (see Supplementary Table 1). Examples of act1-CUP1 genes that conferred survival at the highest copper concentrations $(1.5 \mathrm{mM}$ for prp18 $\Delta C R$ yeast and $2 \mathrm{mM}$ for wild-type yeast) from the libraries were sequenced.

Selected sequences and sequence statistics for winners are shown in Figure 1. From the $5^{\prime}$ splice site libraries (Fig. 1B), A was the predominant base at every position except -2 in the prp $18 \Delta C R$ winners, as expected if the bases pair with $\mathrm{U}_{4}-\mathrm{U}_{7}$ in loop 1 of $\mathrm{U} 5$. In the prp18 $\Delta C R$ winners, position -1 was $100 \% \mathrm{~A}$, whereas the wild-type winners had $25 \% \mathrm{C}$ at -1 . From the $3^{\prime}$ splice site libraries (Fig. 1C), there were two primary prp $18 \Delta C R$ winners, |ACA and |AAA, and all sequences had an A at position +1 ; the wild-type winners did not have a clear consensus. The combined library winners (Fig. 1D) were more complicated and showed many of the same general trends as the individual libraries.

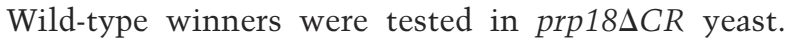
Many conferred high copper resistance, but a significant fraction did not (Fig. 2). All of the wild-type 5' splice site winners ending with $\mathrm{C}$ had the sequence NAACl and conferred low copper resistance on prp18 $\Delta C R$ yeast (Fig. 2 , \#5). C at position -1 does not ensure a poor $5^{\prime}$ exon, since exon1 ends with $C$ in two prp $18 \Delta C R$ winners, AATC|AAT (Fig. 2, \#29) and AGTC|AAC. The wild-type $3^{\prime}$ splice site winners conferred variable copper resistance on prp18 $\mathrm{CR}$ yeast; exon sequences starting with a pyrimidine were worse (TCTG|TTG and TCTG|CAA in Fig. 2, \#8 and \#12) than those starting with a purine, and A was reliably better than $\mathrm{G}(\# 15)$. We also analyzed 32 act1-CUP1 plasmids from the combined library that allowed wild-type yeast to grow at $1 \mathrm{mM} \mathrm{CuSO}_{4}$ (essentially unselected in the screen, with a 95\% survival rate). Of these, one third, including CTTC|CAA and CCCG|ACC (Fig. 2, \#23 and \#24), conferred low cop- 
Crotti et al.

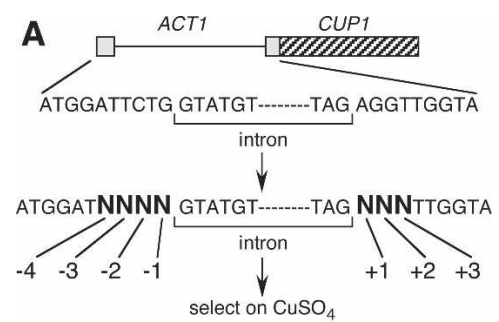

B

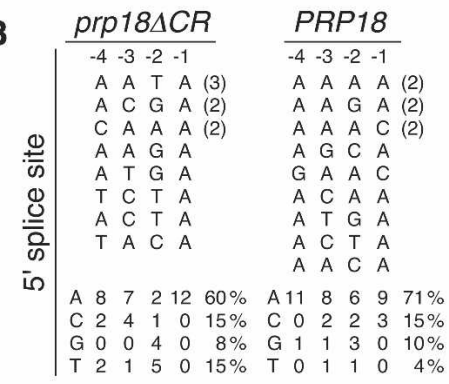

C

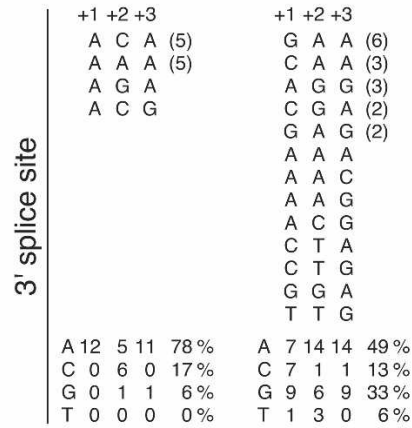

D

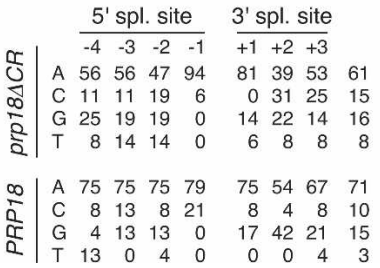

Figure 1. Screen of exon mutants. (A) Schematic of the construction of the libraries, showing the positions of the randomized bases within ACT1-CUP1. (B) Winner sequences from a library with randomized 5' splice sites with a wild-type 3' splice site in prp18 $\triangle C R$ and wild-type yeast. Twelve sequences were analyzed from each strain. Numbers to the right of sequences indicate multiple identifications of the same sequence. Statistics are shown with the number of occurrences of each base at each position and overall percentages of each base. $(C)$ Winner sequences from a library of randomized $3^{\prime}$ splice sites with a wild-type $5^{\prime}$ splice site in $\operatorname{prp} 18 \Delta C R$ and wild-type yeast. Twelve prp18 $\triangle C R$ and 24 wild-type sequences were analyzed. $(D)$ Statistical results for winner sequences from a library with both $5^{\prime}$ and $3^{\prime}$ splice sites randomized from prp18 $C R$ and wildtype yeast. The percentage of each base at each position is shown. Thirty-six prp18 $\triangle C R$ and 24 wild-type sequences were analyzed.

per resistance on prp18 $\Delta C R$ yeast. Winners from all the screens were evaluated in wild-type yeast. All act1CUP1 plasmids tested conferred very similar copper re- sistance on wild-type yeast (Fig. 2) despite the apparent selection of preferred sequences in the screens (Fig. 1). Small differences accounted for the selection from the libraries (see Supplementary Fig. 1).

The screen and the initial analysis showed that altering the sequences of the end of either of the ACT1-CUP1 exons could significantly change the copper resistance conferred to prp18 $\triangle C R$ yeast but not wild-type yeast.

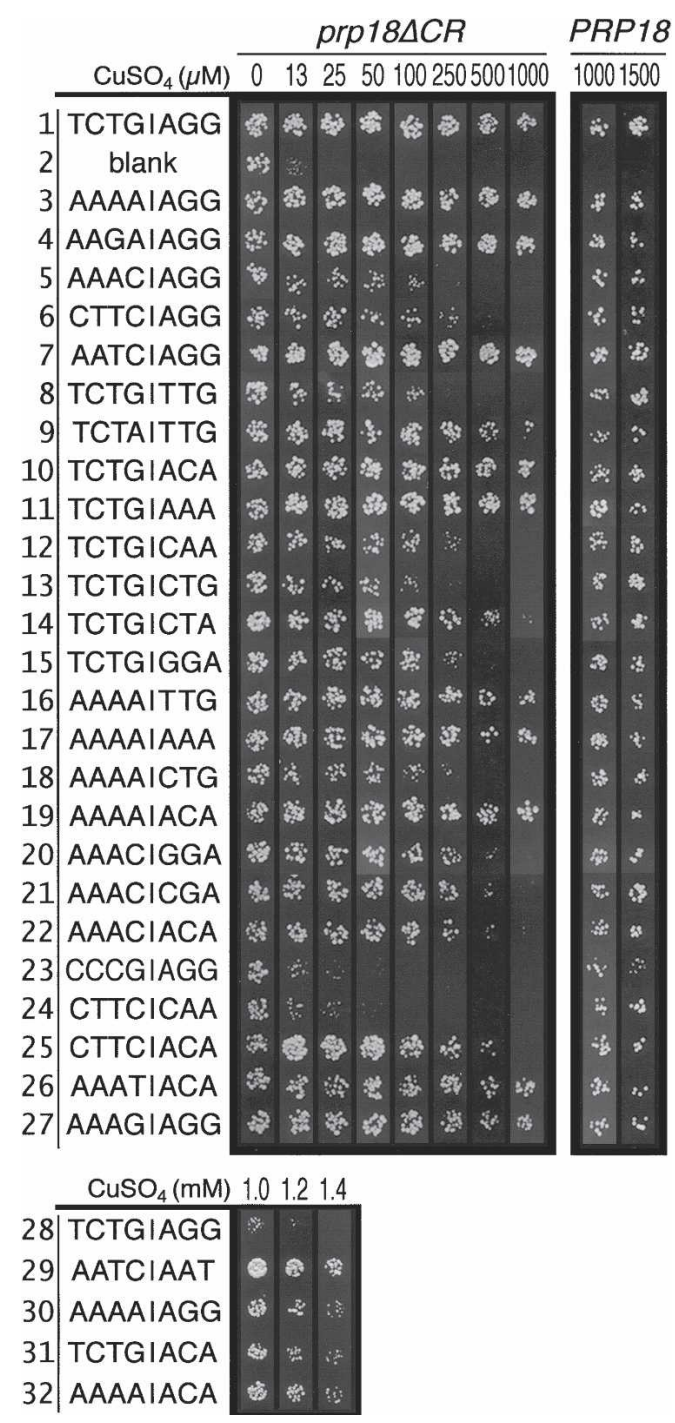

Figure 2. Copper resistances of reporter yeast with mutant act1-CUP1 plasmids. Growth of prp18 $\triangle C R$ and wild-type reporter yeast harboring the act1-CUP plasmids whose exon end sequences are shown at the left was tested at the $\mathrm{CuSO}_{4}$ concentrations indicated at the top of each panel. Sequences are shown as $3^{\prime}$ end of exon $115^{\prime}$ end of exon 2 . The panel in the bottom left shows selected exon mutants compared with wildtype ACT1 in prp18 $A C R$ yeast at high copper concentrations. prp18 $\triangle C R$ yeast were grown for 3-6 d, depending on the $\mathrm{CuSO}_{4}$ concentration. For PRP18 yeast, low copper concentrations are omitted for conciseness; CCCG|AGG (\#23) conferred slightly lower copper resistance to wild-type yeast than did the other plasmids. Each of the three panels is a composite from a single experiment. 
Hence, the results strongly supported our initial hypothesis.

\section{Defining better and poorer splice sites}

We sought to understand the characteristics of the exon sequences that produced better and poorer prp18 $\triangle C R$ splicing substrates. We started with the exons from our screens, recombining them to isolate the effects of $5^{\prime}$ and 3 ' exon sequences, and we made new exon mutants to examine specific bases. We analyzed 170 exon mutants, and we summarize the salient features of our results. Representative mutants are shown in Figure 2 and are referred to by number in the text. All the results, together with a comprehensive description, are shown in Supplementary Table 3.

5' splice sites The screen showed that $\mathrm{A}$ at the $3^{\prime}$ end of exon1 was important for good splicing in prp18 $\triangle C R$ yeast (Fig. 1B,D). We compared bases at the -1 position in the context AAAN|AGG (|AGG is wild-type ACT1) and found that $\mathrm{A}>\mathrm{G} \gg \mathrm{C}$ with $\mathrm{A}$ conferring 10 times the copper resistance of $C(\# 3, \# 5, \# 27, \# 30)$. In weaker overall contexts, A at position -1 was substantially better than G; thus, TCTA|TTG (\#9) and CCCA|ACC conferred higher copper resistance than TCTG|TTG (\#8) and CCCG|ACC. Splicing yields a stop codon in AAAT|AGG; using different 3' exons, we found that AAAA| was somewhat better than AAAT|, which was better than AAACI (\#19,\#22,\#26). The analyses showed that an $A$ at position -1 was a key determinant of efficient splicing and was sufficient to ensure good splicing of all substrates tested except those where the first base of exon 2 was a C. The superiority of A and G supported the idea that base -1 pairs to $\mathrm{U}_{4}$ in loop 1 of $\mathrm{U} 5$.

The $5^{\prime}$ exon screen suggested that $\mathrm{T}$ was the best base at position -2 (Fig. 1B), an idea that was bolstered by the finding that AATCI (\#7, \#29) conferred much higher copper resistance than AAACl (\#5). We compared bases at the -2 position in the AANCl context; $\mathrm{A}$ at -2 was especially poor, and the overall order was $\mathrm{T}>\mathrm{C}>\mathrm{G}>\mathrm{A}$ (\#7, \#5; data not shown). The superiority of $\mathrm{T}$ at -2 was also shown for $5^{\prime}$ exons ending with $G$, such as TCTG|AGG (wild-type ACT1), which was fourfold better than TCCG|AGG. For position -2 , pairing with $U_{5}$ does not explain the preference for $T$, and the ordering of base preferences seems to be opposite the base-pairing expectation.

At positions -3 and 4 the As in the consensus winner sequences (Fig. 1B,D) that could pair with Us in loop 1 were superior bases, as shown in the comparison of AATC|AGG (\#7) with CTTC|AGG (\#6) and the fourfold superiority of TATG|TTG to TCTG|TTG. We used AAAA|, which conferred very high copper resistance on prp18 $\triangle C R$ yeast in most contexts, as a reference $5^{\prime}$ exon.

3' splice site The sequences |ACA and |AAA accounted for 10 of the 12 winners in prp18 $\triangle C R$ yeast (Fig. 1C), and subsequent results confirmed that these sequences worked well (\#10,\#11, \#31). An A at position +1 was the most important determinant in exon2. Either pyrimidine at +1 was usually poor, as shown by TCTG|TTG (\#8) and TCTG|CAA (\#12). G at +1 was generally better than either $\mathrm{C}$ or $\mathrm{T}$. Pairing of base +1 to $\mathrm{U}_{4}$ could account for the observed base preferences. |AGG, the wild-type ACT1 sequence, can pair perfectly to loop 1 , but it was inferior to |ACA and |AAA (e.g., comparing \#28 and \#31, or \#5 and \#22), and |TGG was fourfold worse than |TCA. A at position +3 was selected in the prp $18 \Delta C R$ screen (Fig. 1C). With a wild-type exon1 sequence, |CTA was better than ICTG (\#13,\#14), suggesting some role for base +3 .

Combinatorial effects The effects of mutations at both the $5^{\prime}$ and $3^{\prime}$ splice sites were generally additive, and a good site in one exon compensated for a poor site in the other. Combining the weak AAAC| site with the strong IACA site improved copper resistance (\#5 vs. \#22); likewise, |TTG was improved by combination with AAAA| (\#9 vs. \#16). Combination of two weak sites, as in AAAC|CAA or CTTC|CAA (\#24), resulted in copper resistances as low as $25 \mu \mathrm{M}$, and combination of two strong sites, as in AAAA|ACA (\#32), gave resistances $>1 \mathrm{mM}$.

Some combinatorial effects were more complicated. AAAA| markedly improved |TNN (\#8 vs. \#16) or |GNN exon2 sites but had little effect on weak |CNN sites (\#13, \#18). Curiously, one of our poorest pre-mRNAs, AAAC|CAA, was improved fourfold by the exon2 sequence |CGA (\#21), although |CGA was otherwise a weak sequence.

Mutations in the exon sequences at the splice junctions had large effects on copper resistance in prp18 $\triangle C R$ yeast. Many of the effects can be explained as strengthening or weakening base-pairing interactions between the exons and loop 1 of U5, but the current, prevailing model of base-pairing between loop 1 and exon 1 provided only part of the explanation for our observed sequence preferences (see Discussion).

\section{Effect of exon mutations on splicing}

Our act1-CUP1 pre-mRNAs have exonic mutations that could affect processes after splicing. To show that the changes in copper resistance were caused specifically by changes in splicing, we analyzed the splicing of the act1CUP1 pre-mRNAs in vivo and in vitro.

In vivo splicing We assayed splicing in vivo by primer extension. In prp18 $\triangle C R$ yeast, the levels of mRNAs correlated well with the observed resistance to copper (Fig. 3A). For example, with good substrates like AAAA|ACA (Fig. 3A, lane 12) and AATC|AGG (Fig. 3A, lane 5) mRNA levels were high, whereas poor substrates like CTTC|CAA (Fig. 3A, lane 14) and CCCG|AGG (Fig. 3A, lane 7) had lower mRNA levels. Amounts of mRNA ranged from 1.3-fold more than wild-type ACT1 mRNA to fivefold less, although we are cautious in comparing RNA amounts among different yeast cultures because the copy number of the $2 \mu$ ACT1-CUP1 plasmid can fluctuate. Substrates that gave lower levels of mRNA 


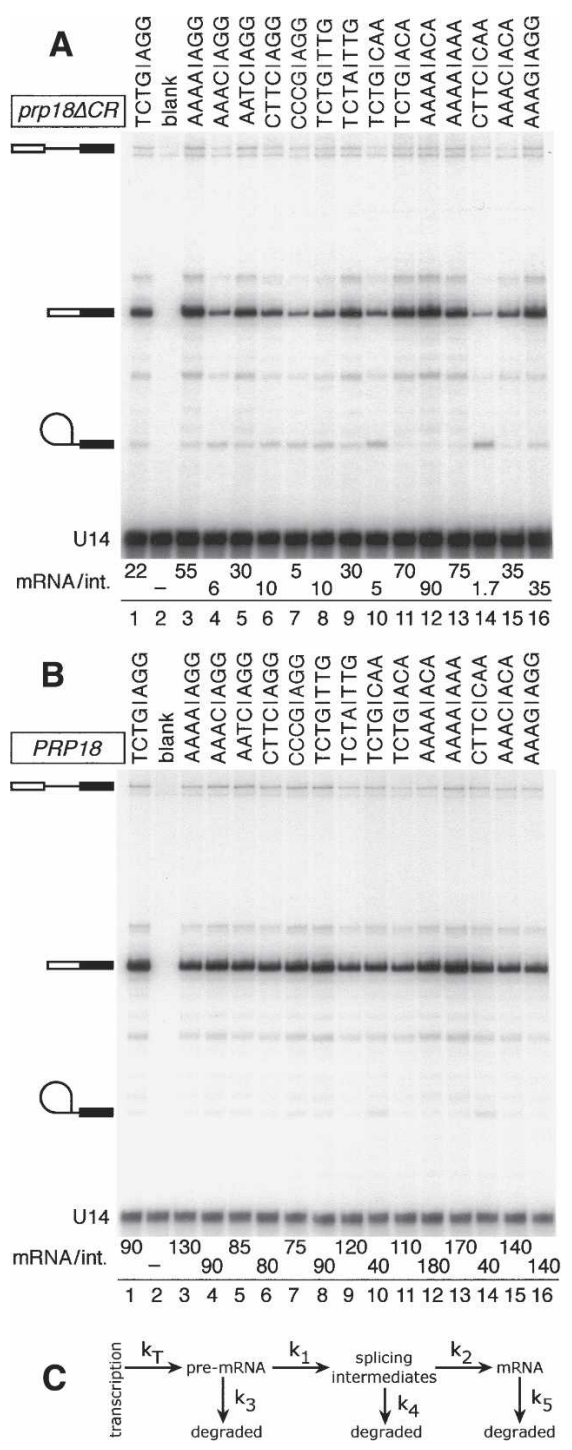

Figure 3. Primer extension analysis of splicing of exon mutant pre-mRNAs. Primer extension products from RNA isolated from $\operatorname{prp} 18 \Delta C R(A)$ and wild-type yeast $(B)$ are displayed. The sequences of the exon ends in the ACT1-CUP1 plasmid are shown at the top of each panel. The positions of pre-mRNA, lariat intermediate, and mRNA, and of the U14 standard, are indicated at the left. The mRNA:intermediate ratio is shown below each lane. Different-length exposures of parallel experiments are shown in $A$ and $B$. Copper resistances for these plasmids are shown in Figure 2. $(C)$ Kinetic scheme for analyzing splicing results (Fouser and Friesen 1986). Each step is described by one rate constant, $k$, that represents the rate-limiting stage in that step of the pathway. In vivo, the RNAs are presumably at steady state, giving $k_{2}=k_{5} \cdot[\mathrm{mRNA}] /[$ intermediates]; that is, the second-step rate is directly proportional to the ratio of mRNA to intermediates (Fouser and Friesen 1986; Frank and Guthrie 1992). If $k_{5}$ is the same for different mRNAs, then relative $k_{2}$ values can be measured, but the in vivo data cannot prove this assumption. Variation in the stabilities of intermediates $\left(k_{4}\right)$ does not affect calculation of $k_{2}$.

had higher levels of splicing intermediates, consistent with a lower second-step rate; for example, AAAA|ACA had a very low level of lariat intermediate (Fig. 3A, lane
12), whereas CTTC|CAA had sevenfold more intermediate, a level similar to that of its mRNA (Fig. 3A, lane 14). The levels of lariat intermediates varied depending on the efficiency of the second step but did not accumulate to high levels (see Discussion). No significant differences in the amounts of pre-mRNA were seen among the substrates, consistent with the idea that the effects are specific to the second step.

We interpret our splicing results using the two-step kinetic scheme shown in Figure 3C and described in its legend. In this model, $k_{2}$, the rate constant for the second step, is directly proportional to the ratio of mRNA to intermediates, and this ratio is shown for each act1CUP1 in Figure 3. The calculated second-step rates varied by 50 -fold. The worst substrate, CTTC|CAA, gave a ratio of 1.7 and the best, AAAA|ACA, 90. The $k_{2}$ values correlated very well with the observed copper resistance and argue that the exon mutations specifically affect the second step (Figs. 2, 3; Table 1). The results cannot prove that $k_{2}$ is changing because the three RNA levels that can be measured in vivo are insufficient to determine the five rate constants in our simple model. Changes in $k_{4}$ and $k_{5}$ could give the results we observe; however, the consistent increase in intermediate levels when product levels decrease is most simply explained by changes in $k_{2}$.

In wild-type yeast, all the act1-CUP1 substrates spliced well and produced similar (within twofold)

Table 1. In vitro and in vivo rate constants for the second step of splicing

\begin{tabular}{|c|c|c|c|c|c|c|}
\hline \multirow[b]{2}{*}{ Prp18 } & \multicolumn{3}{|c|}{ In vitro } & \multicolumn{2}{|c|}{ In vivo } & \multirow[b]{2}{*}{$\begin{array}{l}\mathrm{Cu}^{++} \\
\Delta \mathrm{CR}\end{array}$} \\
\hline & $\begin{array}{l}\text { Wild } \\
\text { type }\end{array}$ & $\Delta \mathrm{CR}$ & $\Delta$ & $\begin{array}{l}\text { Wild } \\
\text { type }\end{array}$ & $\Delta \mathrm{CR}$ & \\
\hline AAAA|AAA & 1.2 & 0.7 & 0.09 & 1.8 & 0.8 & 1.2 \\
\hline AAAA|AGG & 1.3 & 0.6 & 0.025 & 1.4 & 0.6 & 1.1 \\
\hline AATC|AAT & 1.2 & 0.5 & 0.05 & 1.6 & 0.7 & 1.3 \\
\hline AAAT|ACA & 1.2 & 0.45 & 0.035 & 1.7 & 0.9 & 1.0 \\
\hline TCTG|AGG & 1 & 0.35 & 0.015 & 1 & 0.25 & 1.0 \\
\hline AAAC|ACA & 0.9 & 0.2 & 0.01 & 1.5 & 0.4 & 0.5 \\
\hline AAAT|AGG & 0.8 & 0.2 & 0.006 & - & - & - \\
\hline TCTG|TTG & 0.9 & 0.15 & 0.015 & 1.0 & 0.1 & 0.2 \\
\hline AAAC|AGG & 0.7 & 0.15 & 0.004 & 1.0 & 0.07 & 0.15 \\
\hline AAAC|CAA & 0.5 & 0.07 & 0.005 & 0.9 & 0.05 & 0.1 \\
\hline СТТС|CAA & 0.5 & 0.05 & 0.0007 & 0.5 & 0.02 & 0.02 \\
\hline
\end{tabular}

In vitro rate constants $\left(k_{2}\right.$ in Fig. $\left.3 C\right)$ were determined from experiments like those shown in Figure 4. For wild-type ACT1 (TCTG|AGG, shown in bold) with wild-type Prp18, $k_{2}=1.3$ $\mathrm{min}^{-1}$, other in vitro values for $k_{2}$ were normalized to this number to facilitate comparisons. Relative values for $k_{2}$ in vivo were determined from the mRNA to intermediate ratios (Fig. 3) normalized to the ratio of 90 for wild-type ACT1 in wild-type yeast. The copper resistance conferred by the each act1-CUP1 plasmid on prp18 $\triangle C R$ yeast is shown (Fig. 2). AAAT|AGG has a stop codon in its mRNA and cannot be used in vivo. In vitro experiments were reliably reproduced to within $15 \%$ for Prp $18 \Delta$ CR $(30 \%$ for $\Delta \operatorname{Prp} 18)$. In vivo $k_{2}$ values $\geq 1$ and in vitro $k_{2}$ values $<0.01$ were difficult to measure precisely because of the small amounts of intermediates (Fig. 3) or products (Fig. 4B). 
amounts of mRNA (Fig. 3B). Lariat intermediates, which were identified by comparison of mobility with prp18 $\triangle C R$ intermediates, were present at $\sim 1 \%$ of the level of mRNA. In wild-type yeast the ratio of mRNA to intermediates varied about fourfold. The wild-type yeast produced about fourfold more act1-CUP1 mRNA than prp18 $\triangle C R$ yeast for good substrates; some of this difference is likely related to splicing defects in prp18 $C$ CR yeast, but levels of intronless mRNAs are also lower in prp18DCR yeast (Bačíková and Horowitz 2005).

In vitro splicing To determine definitively whether the exon mutations affected the second step of splicing, we tested the splicing of 10 representative exon mutants in vitro using extracts with no Prp18, with Prp18 $\Delta$ CR, or with wild-type Prp18 protein. Time courses of splicing allow quantitative evaluation of both steps of splicing (Horowitz and Abelson 1993b) and avoid the uncertainties inherent in the in vivo measurements.

Complete assays of two substrates, AAAA|AAA and CTTC|CAA, are shown in Figure 4, and rate constants are tabulated in Table 1. Extract from a prp18-knockout strain was assayed alone or supplemented with purified Prp18 CR or Prp18 protein, using sufficient protein to give maximal activity. For AAAA|AAA, a superior substrate (Fig. 2, \#17), second-step activities with Prp18 $\Delta$ CR and wild-type Prp18 were similar; the second step with Prp18 CR was $\sim 1.7$-fold slower (Fig. 4A,C). However, for CTTC|CAA, a poor substrate (Fig. 2, \#24), the second step with Prp18 $\Delta$ CR was 10 -fold slower than with wildtype Prp18. In splicing reactions with Prp18 $\Delta$ CR, inter- mediates accumulated and were slowly spliced to products. We carried out parallel assays of nine more substrates with exon mutations (see Supplementary Figure 2). The in vitro second-step rates in Prp $18 \Delta$ CR extracts varied 14-fold (Table 1) and were well correlated with the copper resistance conferred by the corresponding act1CUP1 plasmid in prp18 $C$ CR yeast. Mutations at both the $5^{\prime}$ and $3^{\prime}$ splice sites affected the rate of the second step. For closely related exon mutants, such as AAACl and AATC|, or |ACA and |AGG, the differences in the second-step rates correlated well with the copper resistances. A comparison of AAAT| to AAAC| paired with either |ACA or |AGG (wild-type) showed that AAAT| was better in both contexts.

In the absence of Prp18, the second step of splicing was very slow, and the same trends as in Prp18DCR-reconstituted extracts were seen. For AAAA|AAA, spliced mRNA formed from intermediates $~ 13$-fold more slowly than in wild-type extract (Fig. 4). For CTTC|CAA, intermediates accumulated but only a trace of mRNA was made; our estimate of its rate was $>500$-fold lower than in wild-type extract (Fig. 4; Table 1). The ordering of the substrates by rate in extracts lacking Prp18 was substantially the same as in Prp $18 \Delta \mathrm{CR}$ extracts, but the rates were lower. We interpret the $\Delta \operatorname{Prp} 18$ results as showing the loss of two distinct functions (Bačíková and Horowitz 2002): first, the loss of its conserved region, which is exon sequence dependent, and, second, the loss of its Slu7-binding activity, which is not. Exon mutations also affected the copper resistance of prp18-knockout yeast (data not shown), consistent with the in vitro results.

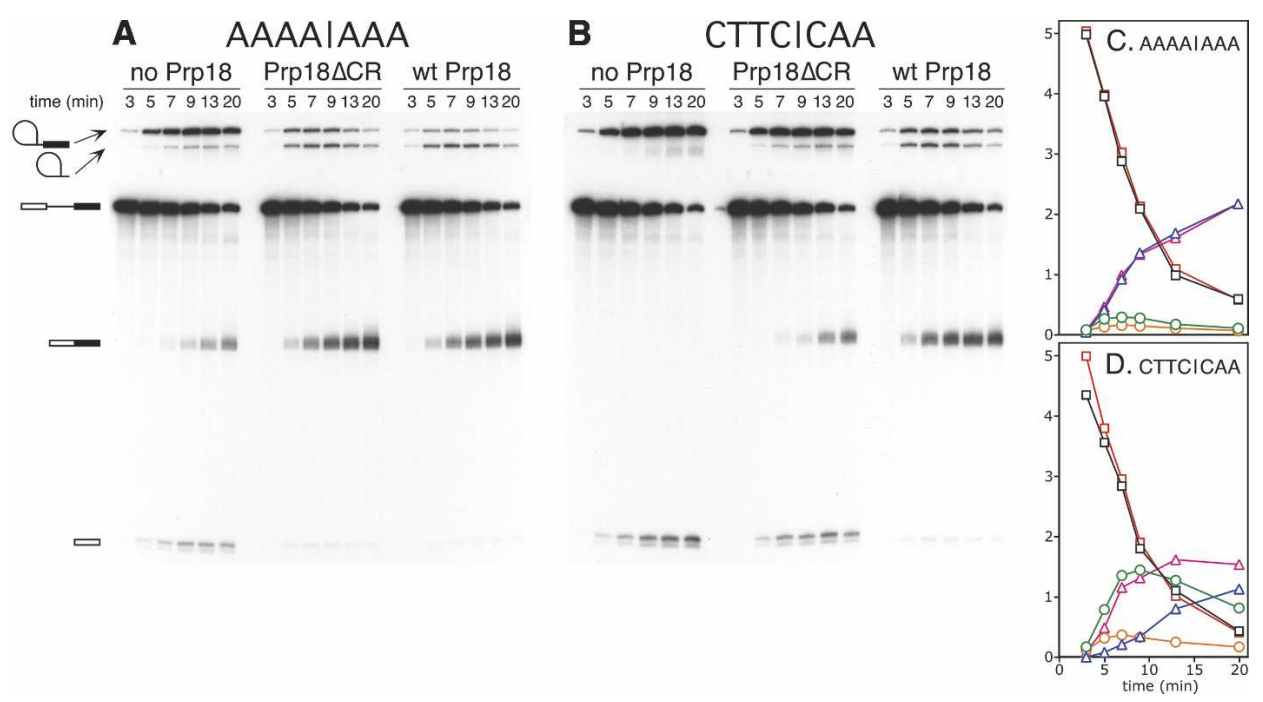

Figure 4. Splicing of two exon mutant substrates in vitro. $A C T 1$ substrates with the exon mutations shown at the top of $A$ and $B$ were spliced in vitro in the absence of Prp18, in the presence of Prp18ACR protein, and in the presence of wild-type Prp18 protein, as indicated. Aliquots were withdrawn at the times indicated along the top of each gel to generate the displayed time courses. $B$ shows one exposure of a single experiment with the sections rearranged for comparison with $A$. Relative molar amounts of RNA species in the Prp18 CR and wild-type Prp18 time courses are graphed in $C$ and $D$. (Black square) Prp18 CR pre-mRNA; (red square) wild-type Prp18 pre-mRNA; (green circle) Prp18 $\Delta$ CR lariat intermediate; (orange circle) wild-type Prp18 lariat intermediate; (blue triangle) Prp18 mRNA; (magenta triangle) wild-type Prp18. The graphs show how $k_{2}$ was calculated using the scheme in Figure $3 \mathrm{C}$. In vitro, $k_{5} \ll k_{2}$ (i.e., mRNA is produced much faster than it is degraded), leading to $k_{2} \approx \Delta[\mathrm{mRNA}] /(\mathrm{t} \text {.[intermediates] }]_{\text {avg. }}$ ); that is, the slope of the [mRNA] versus time graph divided by the [intermediates] (Horowitz and Abelson 1993b). $k_{2}$ was calculated for each interval, and the best estimates of $k_{2}$ are shown in Table 1 . 
In extracts reconstituted with wild-type Prp 18 protein, the rate of the second step varied slightly with exon sequence (Table 1). The second-step rates decreased about twofold for the substrates that are worst in $\operatorname{prp} 18 \Delta C R$ yeast, suggesting that subtle effects on wild-type splicing are exacerbated in Prp $18 \Delta$ CR splicing.

No significant effects on the first step of splicing were observed. For example, AAAA|AAA and CTTC|CAA had essentially the same first-step rate in all the assays (Fig. 4; see Supplemental Material). Differences in $k_{1}$ values were small and did not affect calculation of $k_{2}$. There were no significant differences in the stabilities of the pre-mRNAs, the intermediates, or the mRNAs.

The results demonstrate that the exon mutations specifically affect the second step of splicing in Prp18 $\Delta$ CRreconstituted extracts, as well as in extracts lacking Prp18, and have little effect in wild-type extracts. The comparison in Table 1 shows that the in vitro secondstep rate constants and the relative in vivo rates are in excellent agreement and, further, that the rates correlate very well with the copper resistances.

\section{Effects of exon mutations in AT-AC substrates}

To determine whether exon mutations affect splicing in wild-type yeast, we used a much less efficiently spliced substrate that has an AT-AC intron (Burge et al. 1998). In yeast, AT-AC introns are spliced by the U1-U2 spliceosome. Both steps of splicing are slow (Parker and Siliciano 1993; Chanfreau et al. 1994).

We constructed AT-AC ACT1-CUP1 reporters (Kivens and Siliciano 1996) with wild-type and mutant exon sequences, and we assayed splicing by copper resistance and primer extension. The wild-type exon act1, TCTG|AT-AC|AGG (exon1|intron|exon2), conferred very low copper resistance (Fig. 5), about twice that of a blank plasmid, as reported (Kivens and Siliciano 1996). Altering the act 1 exons to AAAA|AT-AC|AAA - better sequences from the prp18 $\triangle C R$ results-improved the copper resistance about fourfold (Fig. 5). Most of the improvement resulted from changing the 5 ' exon to AAAA| with the $3^{\prime}$ exon change to |AAA contributing only marginally. The increase in copper resistance was abolished if either terminal exon base was changed to $\mathrm{C}$ (Fig. 5; data not shown), paralleling the behavior of GT-AG introns in $\operatorname{prp} 18 \Delta C R$ splicing.

The changes in copper resistance were accompanied by commensurate changes in the level of correctly spliced mRNA, determined by primer extension (Fig. 6A) and sequencing of RT-PCR products. The levels of mRNA correlated well with the measured copper resistances; TCTG|AT-AC|AGG yielded $\sim 3 \%$ as much mRNA as wild-type ACT1 (Fig. 6A, lane 3), whereas AAAA|AT-AC|AAA yielded $\sim 10 \%$ as much (Fig. 6A, lane 4). Intermediates accumulated with all the AT-AC substrates, and the levels of intermediates and mRNA were inversely correlated for all the mutants. The ratio of products to intermediates provides an estimate of the rate of the second step (Fig. 3C). The second step with AAAA|AT-AC|AAA was about sixfold faster than with

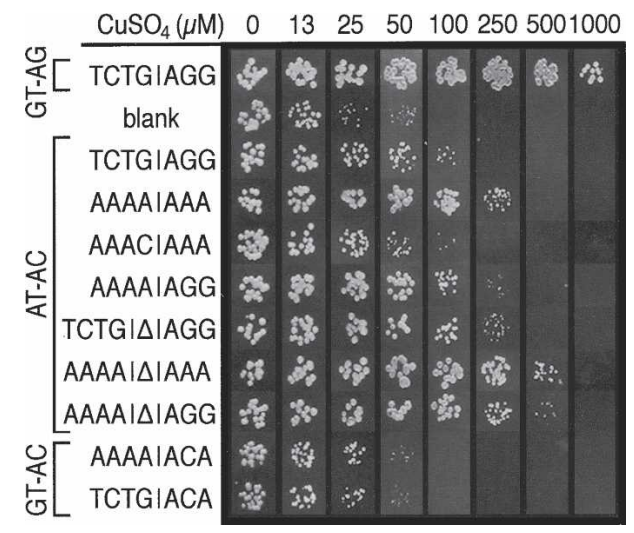

Figure 5. Copper resistances of reporter yeast with AT-AC intron plasmids. Wild-type reporter yeast bearing the act1-CUP1 plasmids shown at the left were grown on plates with $\mathrm{CuSO}_{4}$ at the concentrations indicated at the top. The act1-CUP1 exon sequences are shown just to the left of the composite photograph, and the terminal intron bases are shown along the left border. Introns with the $\Delta-9,-10$ deletion are indicated by a " $\Delta$ " between the exon sequences. The image is a composite from parallel experiments.

TCTG|AT-AC|AGG, and second-step rates correlated well with copper resistance. Primer extension results for two other substrates (Fig. 6A, lanes 5,6) paralleled their copper resistances. Levels of pre-mRNAs did not change appreciably among the mutant substrates, suggesting that first step rates were not changing significantly among the mutants, although the possibility that large $k_{3}$ values obscured changes in $k_{1}$ could not be excluded.

Exon mutations improved the second step of splicing of AT-AC substrates in vitro: AAAA|AT-AC|AAA was spliced better than the "wild-type" TCTG|ATAC|AGG (Fig. 6B). The AT-AC substrates were spliced very inefficiently (Fig. 6B, lanes 7-12). Both AT-AC substrates shown in Figure 6B were spliced slowly through the first step, but only the AAAA|AT-AC|AAA intermediates were spliced significantly through the second step to make product mRNA. Comparing amounts of intermediates and products strongly suggested that $k_{2}$ for the AAAA|AT-AC|AAA was higher than for TCTG|AT-AC|AGG, consistent with the in vivo results, but the slow splicing and difficulty of quantitating the RNAs precisely precluded application of our kinetic model.

Kivens and Siliciano (1996) found that mutation of bases upstream of the $3^{\prime}$ splice site improved the second step of splicing of ACT1 AT-AC introns. We used the two-base deletion $\Delta-9,-10$ as an example of this type of mutant. The TCTG|AT- $-\Delta-9,-10-\mathrm{AC} \mid \mathrm{AGG}$ and AAAA|AT-AC|AAA ACT1-CUP1 plasmids conferred similar copper resistance (Fig. 5) and gave similar levels of spliced mRNA (Fig. 6A, lanes 4,7). We combined the two mutations to make AAAA|AT $-\Delta-9,-10-$ AC|AAA. The effects of the two mutations were additive, yielding an AT-AC ACT1-CUP1 substrate that allowed growth up to $500 \mu \mathrm{M}$ copper (Fig. 5) and produced $25 \%$ as much mRNA as wild-type GT-AG ACT1-CUP1 (Fig. 6A, lane 


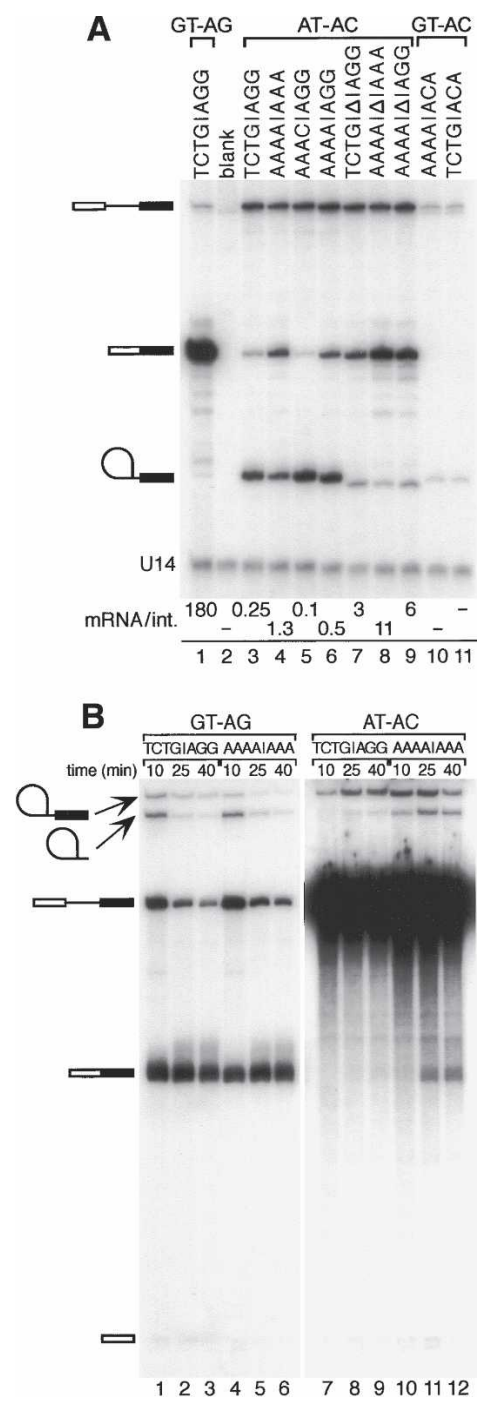

Figure 6. Splicing of AT-AC introns. (A) Primer extension products from mutant act1-CUP1 RNAs isolated from wildtype yeast are shown. The terminal bases of the introns are shown at the top, and the sequences at the ends of the exons are shown above the gel. Introns with the $\Delta-9,-10$ deletion are indicated by a " $\Delta$ " between the exon sequences. The positions of the splicing RNAs and the U14 reference are shown at the left. At the bottom, the ratios of mRNA to lariat intermediate are shown where they could be determined. For GT-AC introns, only a hint of product was observed, and further RT-PCR analysis did not reveal any other products. $(B)$ Time courses of in vitro splicing of four pre-mRNAs with wild-type extract are shown. The terminal bases of the introns are shown at the top, and the sequences of the ends of the exons are shown below them. Reaction times are shown above the gel, and the positions of the splicing RNAs are indicated at the left.

8). The rate of the second step in vivo was correspondingly increased, by 50 -fold compared with TCTG|ATAC|AGG.

Better exon sequences only increased copper resistance if the introns had both the AT and AC changes. AT-AG and GT-AC introns provided essentially no copper resistance above background (Fig. 5; data not shown).
For GT-AC intron substrates, whose first step proceeds at normal rates (Rymond and Rosbash 1985), practically no intermediates accumulated and mRNA was not detectable (Fig. 6A, lanes 10,11). AT-AC intermediates are likely stabilized by interaction of the terminal bases of the intron (Scadden and Smith 1995; Tarn 1996). Without this interaction the GT-AC intermediates may be degraded early in the second step before the exon mutations affect splicing, or the GT-AC introns may have unfavorable interactions that cannot be overcome by the exon mutations.

\section{Discussion}

We have investigated the role of exon bases at the splice junctions in the second step of splicing. Standard models show the bases at the ends of both exons pairing with bases $\mathrm{C}_{3} \mathrm{U}_{4} \mathrm{U}_{5} \mathrm{U}_{6}$ in loop 1 of $\mathrm{U} 5$ (Fig. 7A), based primarily on genetic experiments (Newman and Norman 1991, 1992). The hypothesis that Prp18 stabilized the interaction of the exons with U5 during the second step was tested by constructing ACT1-CUP1 reporter libraries in which the exon ends were randomized and screening them in prp18 $\triangle C R$ and wild-type yeast. Altering the exon sequences had a large effect on splicing in prp18 $\triangle C R$ yeast but had little effect in wild-type yeast, implying that Prp18 does stabilize the exon-U5 interactions. The characteristics of the Prp18 $\Delta$ CR protein (Bačíková and Horowitz 2002) imply that the exon sequence dependence in prp18 $\triangle C R$ splicing results from the absence of a stabilizing force in the spliceosome and is not an effect induced by the mutation. We conclude that the sequence preferences result from normal interactions in the spliceosome that must be stronger in prp18 $\triangle C R$ spliceosomes to allow the second step to proceed. This idea is strongly supported by the observation that superior exon sequences accelerated the second step of splicing in wild-type spliceosomes with AT-AC premRNAs that undergo the second step slowly. Analysis of 170 exon mutants in prp18 $\triangle C R$ yeast supports a revised model of the interactions of the exons with U5 during the second reaction (Fig. 7B).

Critical to interpreting the effects we see is our demonstration that the second step of splicing was specifically affected by mutation of the exon sequences. Assays of in vivo splicing provided evidence consistent with specific effects on the second step; relative second-step rates correlated very well with copper resistance. The assay of splicing in vitro was definitive, showing the accumulation of splicing intermediates in the presence of Prp18 CR protein or in the absence of Prp18 as well as the slow splicing of the intermediates to mRNA. We used a straightforward kinetic model of splicing (Fig. 3C) to distinguish first- and second-step effects and effects on RNA stability. Estimation of the second-step rate constants in vivo relied on assumptions about decay rates, whereas the in vitro assays showed the second-step defects clearly and allowed calculation of the second-step rate constants. The calculated in vitro and in vivo rate constants for the second step were in excellent agree- 
Figure 7. Interactions between loop 1 of U5 and the splicing intermediates. (A) Standard model of interactions. Loop 1 is shown in black (numbered as in Newman and Norman [1991]) together with part of stem 1. The paths of the splicing intermediates are in gray with bases $\mathrm{E}_{-5}$ through $\mathrm{E}_{-1}$ at the $3^{\prime}$ end of exon 1 in blue and bases $\mathrm{E}_{+1}$ through $\mathrm{E}_{+3}$ at the $5^{\prime}$ end of exon 2 in magenta. Interactions between loop 1 and exon bases are shown by solid lines. Intron bases are shown in green. $(B)$ Revised model of interactions. At each exon position the preferred base from our prp $18 \triangle C R$ results is shown with its pairing to $\mathrm{U} 5$ indicated. For base $+2, \mathrm{~A}$ and $\mathrm{C}$ were equally good, and its previously inferred pairing to $\mathrm{C}_{3}$ during the second step is indicated by a dashed line (Newman and Norman 1992).
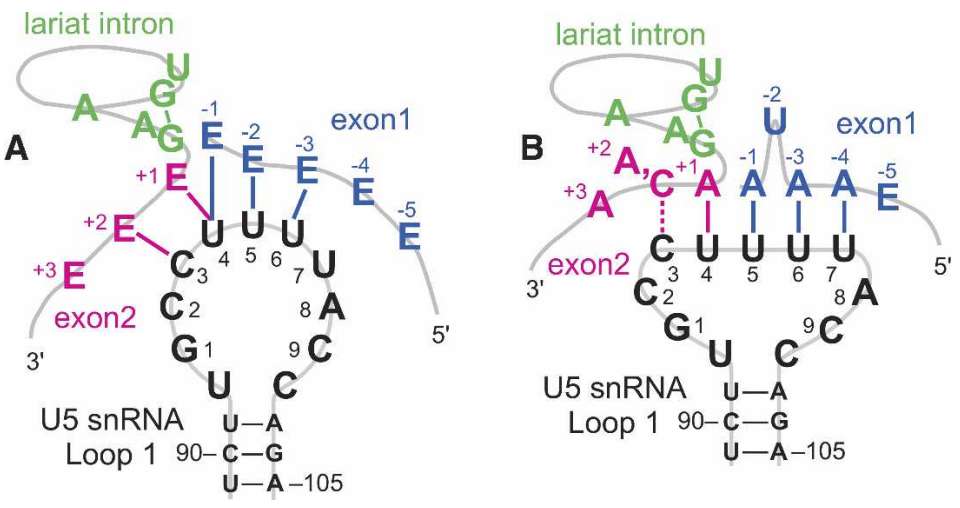

ment. Both correlated extremely well with the copper resistance of indicator yeast, even for pre-mRNAs with subtle differences in exon sequences. Together, our results provide a high level of evidence that the exon mutations specifically affect the second step of splicing in $\operatorname{prp} 18 \Delta C R$ yeast.

\section{The mechanism of action of Prp18}

The second step of splicing is sensitive to the sequences of the exon ends with Prp $18 \Delta$ CR or in the absence of Prp18. The exons both interact with loop 1 of U5, and we conclude that the conserved region of Prp18 stabilizes these interactions during the second catalytic reaction. The conserved region of Prp18 is composed of 25 nearly invariant amino acids that form part of a flexible loop between two adjoining, anti-parallel $\alpha$-helixes (Jiang et al. 2000). In this study, we determined that the Prp18 CCR and Prp18 proteins have half-maximal activities at the same concentration, implying that their affinities for the spliceosome are similar. The result confirms the earlier inference that Prp18 $\Delta$ CR enters the spliceosome normally but lacks a function needed for optimal splicing (Bačíková and Horowitz 2002). Thus,

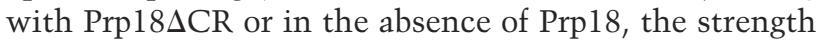
of other interactions becomes critical for good splicing, and we are able to assay interactions of the exons that are normally masked by the actions of proteins.

Combined with earlier results (Zhang and Schwer 1997; Bačíková and Horowitz 2002, 2005; James et al. 2002), our work leads to a model of Prp18 action in which binding of Prp18 to Slu7 and possibly other components of the spliceosome positions the conserved region of Prp18 to facilitate the second reaction. We previously found that alleles of the U5 gene with the mutation $\mathrm{U} 4 \mathrm{~A}$ or $\mathrm{A} 8 \mathrm{C}$ in loop 1 (Fig. 7) suppress the splicing defect of prp18 alleles that encode Prp18 proteins with mutated conserved regions, including prp18 ová and Horowitz 2005). The present work shows directly that Prp18 stabilizes the interaction of the exons with U5. In Prp18 $\Delta$ CR splicing, bases +1 and -1 are important, as is loop 1 base $\mathrm{U}_{4}$ (Fig. 7). The conserved region of Prp18 could interact directly with this central region of the spliceosome, or Prp18 could act less di- rectly, altering the conformation of the spliceosome to stabilize second-step interactions. Prp18 is likely to act together with Prp8 (Teigelkamp et al. 1995; Grainger and Beggs 2005) to hold the exons in position for ligation.

Lariat intermediates did not accumulate to high levels in $\operatorname{prp} 18 \Delta C R$ yeast, although intermediate levels varied depending on the rate of the second step. We think that with Prp18 CCR in the spliceosome, Prp22 binds normally (James et al. 2002). If the second step is slow, Prp22 can cause disassembly of the spliceosome as part of the proofreading of splicing (Mayas et al. 2006). To be effective, the speed of the proofreading reaction $\left(k_{4}\right)$ must be a significant fraction of that of the normal second step $\left(k_{2}\right)$. Hence, if $k_{2}$ falls, intermediates will not accumulate to high levels. Consistent with this idea, intermediates accumulate to higher levels in yeast without Prp18 and in yeast with mutants of $\operatorname{Prp} 18$ that do not enter the spliceosome than in prp18ACR yeast (Bačíková and Horowitz 2005).

\section{Interaction between U5 and the exons during the second step}

Absent the stabilizing effect of the conserved loop of Prp18, the strength of the interactions of the exon bases and loop1 of U5 or other spliceosomal components significantly affects the rate of the second step. Analogous effects are seen in wild-type spliceosomes using mutant transcripts. We interpret the differences in second-step rates as indicators of the stability of the interaction of the exons with the spliceosome. Our results are only partly consistent with the standard model of interaction of the exons with U5, and we propose a revised model of these interactions.

Figure 7 shows the standard model of exon interactions (Fig. 7A) and our proposed model with the best bases at each position from our results (Fig. 7B). Newman and Norman $(1991,1992)$ proposed the base-pairing model based on compensatory mutations in U5. U5 mutations that restored splicing activity of substrates with a G-to-A mutation at either the $5^{\prime}$ or $3^{\prime}$ end of the intron were identified. Pairing of loop 1 bases 5 and 6 with bases -2 and -3 of exon 1 and of bases 3 and 4 with bases +1 and +2 in exon 2 accounted well for the results. An additional, inferred pair of exon 1 base -1 to $\mathrm{U}_{4}$ could juxta- 
pose the exon ends for ligation. Cross-linking studies support this arrangement of loop 1 and the exons (Wyatt et al. 1992; Sontheimer and Steitz 1993; Newman et al. 1995; O'Keefe and Newman 1998; McGrail et al. 2006). The interaction between loop 1 and exon 1 is established before the first step of splicing. Exon2 interacts with loop 1 only after the first step, likely following the action of Prp16 (Schwer and Guthrie 1992).

We found that exon bases -1 and +1 at the exon/intron boundaries were the most important and that A was optimal at both positions, consistent with the base-pairing model (Fig. 7A). The effects of As at +1 and -1 were the clearest in our results, and an $\mathrm{A}$ at position -1 was the single most important determinant of good splicing. Our work is the first to show the dominant effect of this base. At position -1, G could base-pair with the U1 snRNA, but this effect is small in yeast (Lesser and Guthrie 1993), and we did not select $G$ in our screens. At position -2 , $U$, which cannot pair with $U_{5}$, was the consensus winner from the screen and was markedly better than $\mathrm{A}$ in many contexts. A was the consensus winner at both positions -3 and -4 . Overall, the potential of a 5 ' exon end to pair with U5 was correlated with the rate of its splicing, but this explanation is incomplete. Differences between our results and those of the Newman laboratory (Newman and Norman 1991, 1992) might be caused by different contexts of the exon bases studied. More important, the base-pairing of exon 1 to U5 assayed in Newman and Norman (1991) occurs before the first catalytic step, whereas the in vitro splicing experiments show that our effects are specific to the second step.

At the $3^{\prime}$ splice site, our results are in reasonable agreement with the standard model. Both our experiments and those of Newman and Norman (1992) measure second-step effects. At position +1 , the strong preference for A, as well as the superiority of A and G to U and C, supports the idea of pairing to $\mathrm{U}_{4}$. At position $+2, \mathrm{C}$ and A were preferred to the $G$ that could base-pair with $C_{3}$, although the effect of base +2 was smaller than that of +1 . The U2 snRNA may interact with exon 2 and could affect the base preferences (Newman et al. 1995; McGrail et al. 2006).

The exons' geometry before the second reaction apparently creates a conflict: The terminal bases of both exons are proposed to pair with base $\mathrm{U}_{4}$ (Fig. 7A; Newman and Norman 1992). We find that the identities of bases at the ends of both exons are critical at the time of the second reaction (when Prp18 acts). Both bases are optimally A, which individually could be interpreted as base-pairing with $\mathrm{U}_{4}$; however, bases +1 and -1 cannot simultaneously pair with $U_{4}$. Such an interaction would severely distort loop 1 and would not appear to position the exons for the splicing reaction. Our results suggest the revised model of exon arrangement shown in Figure 7B. Following the first step, exon 2 moves to interact with loop 1; concomitantly, base -1 displaces base -2 and pairs with base $U_{5}$ while bases -3 and -4 remain paired, leaving base -2 bulged out of the helix. This model resolves the conflicting interactions with base $\mathrm{U}_{4}$ and explains (1) the preference for $U$ at position -2 , because pairing of base -2 to $U_{5}$ would disfavor this conformation; (2) the weakness of AAACl, because the $\mathrm{A}_{-2}-\mathrm{U}_{5}$ base pair would be stronger than the $\mathrm{C}_{-1}-\mathrm{U}_{5}$ pair that would replace it; (3) the selection of As at positions -3 and -4 ; and (4) the strong preference for A at both exon ends. A key feature of this model is that the exon ends are aligned to form a continuous double helix that positions the 3 ' hydroxyl at the end of exon 1 to attack the phosphodiester at the junction of the intron and exon2, as in Group I self-splicing (Adams et al. 2004). Cross-linking experiments suggest that exon 1 does not move significantly during splicing (Sontheimer and Steitz 1993; Newman et al. 1995; O'Keefe and Newman 1998), and the model is consistent with these results. Other models would also resolve the conflicting interaction at base U4: (1) Exon 1 could slide one base along the U-stretch of loop 1 without a bulged base, or (2) the terminal base of exon 1 could be pushed away from $\mathrm{U}_{4}$ and could interact with other components of the spliceosome so that its $3^{\prime}$ hydroxyl is positioned to attack the phosphodiester linkage at the 3' splice site. Neither of these models explains our results as completely as the bulged-base model. The interactions we show are likely insufficient by themselves to hold the splicing intermediates, and other spliceosomal components will also be important.

\section{Splicing of AT-AC introns}

We showed that exon mutations affected wild-type splicing of an inefficiently spliced ACT1-CUP1 mutant in which the $5^{\prime}$ end of the intron was changed to AT and the $3^{\prime}$ end to AC. In yeast, AT-AC pre-mRNAs are spliced by the U1-U2 spliceosome (Burge et al. 1998), and both steps of splicing are slow (Parker and Siliciano 1993; Chanfreau et al. 1994). We found that the second step of splicing of AT-AC pre-mRNAs was specifically accelerated by altering its exon ends to superior sequences chosen from our results with prp18DCR yeast. Inferior exon sequences did not improve the splicing of the AT-AC substrates. The AT-AC results show that the same interactions that we found were important in prp18 $\triangle C R$ spliceosomes are present in wild-type spliceosomes and can be important in wild-type splicing. Reducing the stability of the spliceosome either by deleting the conserved region of Prp18 or by altering the terminal Gs of the intron can be compensated by better exon sequences that restore stability by increasing the strength of the exons' interactions with U5.

Kivens and Siliciano (1996) found that a variety of mutations in the intron just upstream of the $3^{\prime}$ splice site improved the second step of splicing of AT-AC premRNAs. Individually, our exon mutations or this type of intron mutation increased the rate of the second step by fivefold to 10-fold, and in combination the enhancements were additive, increasing the rate by 50 -fold. The result suggests, but does not prove, that the two types of mutations affect the second step by different mechanisms. Splicing of the best AT-AC pre-mRNA yields $\sim 25 \%$ as much mRNA as wild-type ACT1-CUP1, suggesting that Saccharomyces cerevisiae pre-mRNAs 
could have AT-AC introns, although none is known (Spingola et al. 1999). The combined mutations can defeat the proofreading mechanisms that would normally exclude substrates without GT-AG boundaries. In this view, the strength of the interactions between the premRNA and the spliceosome is modulated to allow efficient splicing without compromising proofreading processes.

ATP hydrolysis by Prp22 causes release of the mRNA after splicing (Schwer and Gross 1998) and could disassemble slow spliceosomes to abrogate splicing of premRNAs with GT-AC introns (Mayas et al. 2006). The duplex formed by loop 1 of U5 with the intermediates or the mRNA is one suggested target of the Prp22 helicase (Schneider et al. 2004). By strengthening the interactions of loop 1 with the intermediates, our exon mutations could slow the action of Prp22, giving a common mechanistic basis for the effects of our exon mutations on ATAC intron splicing and the Prp22 effects on GT-AC introns.

In our AT-AC splicing experiments, the splicing of a very poor substrate was improved by alteration of the exon sequences. The splicing machinery of higher eukaryotes is much more flexible than S. cerevisiae's, and the influence of the exon sequences could be significant. Better exon sequences could compensate for poorer 3' splice sites or for more distant branch sites. In in vitro models of Drosophila sxl splicing, the choice between alternative splice sites is made during the second step (Lallena et al. 2002), and exon sequences could be influential in this kind of selection.

\section{Materials and methods}

Yeast

YLC10 (prp18::KAN ${ }^{x}$ ) was made from the copper reporter strain L5 (MATa cup1s :: ura3 leu2 trp1 ura3-52 lys2 his3 ade) (from J. Pan and C. Guthrie, University of California at San Francisco, San Francisco, CA) (Lesser and Guthrie 1993; Umen and Guthrie 1995) by disrupting PRP18 with $K A N^{\mathrm{r}}$ (Bačíková and Horowitz 2005). Wild-type splicing extracts (Umen and Guthrie 1995) were made from BJ2168 (MATa leu2 trp1 ura3-52 prb11122 pep4-3 prc1-407 gal2) (from B. Schwer, Weill Medical College of Cornell University, New York, NY) or CB018a (MATa

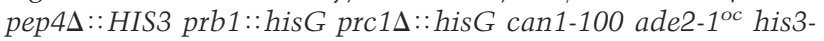
11,-15 leu2-3,-112 trp1-1 ura3-1) (from L. Parkinson and B. Fuller, University of Michigan, Ann Arbor, MI) yeast. Extracts lacking Prp18 were made from CB018a $\Delta 18$, in which PRP18 was replaced with $\operatorname{prp} 18:: K A N^{x}$.

\section{Plasmids}

The libraries of exon mutants were made in the ACT1-CUP1 plasmid pGAC14 (Lesser and Guthrie 1993). pGAC14-Mlu was made by changing the last four bases in the ACT1 exon1 to ACGC to create an MluI site. The last four bases of $A C T 1$ exon 1 in pGAC14-Mlu were randomized by QuikChange Mutagenesis (Stratagene). The mutagenized pool was cut with MluI (to reduce background) before transformation into Escherichia coli. Approximately 8000 colonies were combined to make the random library. The first three bases of exon 2 were randomized using a similar procedure with StuI. The two libraries were recombined to make the large library using the XhoI and BstXI sites in pGAC14. For unknown reasons, the library has an A bias and is $\sim 40 \%$ A overall. Additional exon mutant plasmids were made by standard techniques.

\section{Assay of in vivo splicing}

YLC10 transformed with plasmids bearing a wild-type or mutant allele of PRP18 was used for most copper assays. L5 was used for AT-AC intron assays. Yeast were grown at $34^{\circ} \mathrm{C}$, a semipermissive temperature for prp18 $18 R$ yeast (Bačíková and Horowitz 2002). Copper resistance was determined by streaking or spotting yeast on selective media with different concentrations of $\mathrm{CuSO}_{4}$ (Lesser and Guthrie 1993). For spotting, yeast were disaggregated with EGTA, which did not affect the copper assay. Screens of libraries were done by replica plating at different copper concentrations (Supplementary Table 1). For primer extensions, RNA was prepared from yeast grown at $32^{\circ} \mathrm{C}$ by hot-phenol extraction (Collart and Oliviero 2000). The ACT1CUP primer in exon2 from Siatecka et al. (1999) was used, and the U14 primer U14-14B from Kivens and Siliciano (1996), for normalization of RNA amounts.

\section{In vitro splicing and purification of Prp $18 \Delta C R$}

ACT1-CUP1 pre-mRNA did not splice well in vitro. We made a plasmid that allowed transfer of act1 sequences into a vector for splicing. pDKSa2 was made by introducing a KpnI site into the SP6-actin plasmid (Lin et al. 1985) seven bases downstream from the $3^{\prime}$ splice site (as in pGAC14), and converting the AccI site 97 base pairs (bp) downstream from the $3^{\prime}$ splice site to an NdeI site (because an inverted repeat in the transcript inhibited splicing). Transcripts of pDKSa2/NdeI spliced well and yielded very stable products. For the plasmids for in vitro assay, act1 sequences were amplified by PCR, cut with BamHI and KpnI, and cloned into pDKSa2.

Splicing was carried out at $28^{\circ} \mathrm{C}$ (for AT-AC pre-mRNAs) or $32^{\circ} \mathrm{C}$ (for GT-AG pre-mRNAs) under standard conditions (Lin et al. 1985). One nanogram of Prp18 or Prp $18 \Delta$ CR per microliter of CBO18a $\Delta 18$ extract was added where indicated. Both Prp18 and Prp $18 \Delta$ CR gave maximum activity at $\sim 0.25 \mathrm{ng} / \mu \mathrm{L}$ of extract and half-maximal activity at $0.05 \mathrm{ng} / \mu \mathrm{L}$, similar to previous work (Jiang et al. 2000). Twentyfold more protein did not increase activity.

Prp $18 \Delta$ CR was expressed in E. coli at $21^{\circ} \mathrm{C}$, was fractionated by ammonium sulfate precipitation, and was purified to near homogeneity by chromatography on HS2O (sulfonic acid) at $\mathrm{pH}$ 6.3 followed by HQ20 (quaternary imine) at $\mathrm{pH}$ 8.0. Both Prp18 and Prp $18 \Delta$ CR gave a single sharp peak at $\sim 55,000$ on gel filtration columns (Horowitz and Abelson 1993b).

\section{Acknowledgments}

We thank Michelle Hastings and Javier Cáceres for comments on the manuscript, and Jie Pan and Christine Guthrie for ACT1CUP1 reagents. This work was supported by National Institutes of Health grant GM57267 to D.S.H., by USUHS grant C017HO to D.S.H., and by the Dean's Fund at USUHS.

\section{References}

Adams, P.L., Stahley, M.R., Kosek, A.B., Wang, J., and Strobel, S.A. 2004. Crystal structure of a self-splicing group I intron with both exons. Nature 430: 45-50.

Bačíková, D. and Horowitz, D.S. 2002. Mutational analysis 
identifies two separable roles of the Saccharomyces cerevisiae splicing factor Prp18. RNA 8: 1280-1293.

Bačíková, D. and Horowitz, D.S. 2005. Genetic and functional interaction of evolutionarily conserved regions of the Prp18 protein and the U5 snRNA. Mol. Cell. Biol. 25: 2107-2116.

Burge, C., Padgett, R., and Sharp, P. 1998. Evolutionary fates and origins of U12-type introns. Mol. Cell 2: 773-785.

Chanfreau, G., Legrain, P., Dujon, B., and Jacquier, A. 1994. Interaction between the first and last nucleotides of premRNA introns is a determinant of $3^{\prime}$ splice site selection in S. cerevisiae. Nucleic Acids Res. 22: 1981-1987.

Collart, M.A. and Oliviero, S. 2000. Preparation of yeast RNA by extraction with hot acidic phenol. In Current protocols in molecular biology (eds. F.M. Ausubel et al.), pp. 13.12.1113.12.12. John Wiley \& Sons, Inc., New York.

Company, M., Arenas, J., and Abelson, J. 1991. Requirement of the RNA helicase-like protein PRP22 for release of messenger RNA from spliceosomes. Nature 349: 487-493.

Cortes, J.J., Sontheimer, E.J., Seiwert, S.D., and Steitz, J.A. 1993. Mutations in the conserved loop of human U5 snRNA generate use of novel cryptic $5^{\prime}$ splice sites in vivo. EMBO J. 12: $5181-5189$

Fouser, L.A. and Friesen, J.D. 1986. Mutations in a yeast intron demonstrate the importance of specific conserved nucleotides for the two stages of nuclear mRNA splicing. Cell 45: 81-93.

Frank, D. and Guthrie, C. 1992. An essential splicing factor, SLU7, mediates $3^{\prime}$ splice site choice in yeast. Genes \& Dev. 6: $2112-2124$.

Frank, D.N., Roiha, H., and Guthrie, C. 1994. Architecture of the U5 small nuclear RNA. Mol. Cell. Biol. 14: 2180-2190.

Grainger, R.J. and Beggs, J.D. 2005. Prp8 protein: At the heart of the spliceosome. RNA 11: 533-557.

Horowitz, D.S. and Abelson, J. 1993a. Stages in the second reaction of pre-mRNA splicing: The final step is ATP independent. Genes \& Dev. 7: 320-329.

Horowitz, D.S. and Abelson, J. 1993b. A U5 small nuclear ribonucleoprotein particle protein involved only in the second step of splicing in Saccharomyces cerevisiae. Mol. Cell. Biol. 13: 2959-2970.

James, S.A., Turner, W., and Schwer, B. 2002. How Slu7 and Prp18 cooperate in the second step of yeast pre-mRNA splicing. RNA 8: 1068-1077.

Jiang, J., Horowitz, D.S., and Xu, R.-M. 2000. Crystal structure of the functional domain of the splicing factor Prp18. Proc. Natl. Acad. Sci. 97: 3022-3027.

Jones, M.H., Frank, D.N., and Guthrie, C. 1995. Characterization and functional ordering of Slu $7 p$ and Prp $17 p$ during the second step of pre-mRNA splicing in yeast. Proc. Natl. Acad. Sci. 92: 9687-9691.

Kivens, W. and Siliciano, P.G. 1996. RNA sequences upstream of the 3' splice site repress splicing of mutant yeast ACT1 introns. RNA 2: 492-505.

Lallena, M.J., Chalmers, K.J., Llamazares, S., Lamond, A.I., and Valcárcel, J. 2002. Splicing regulation at the second catalytic step by Sex-lethal involves $3^{\prime}$ splice site recognition by SPF45. Cell 109: 285-296.

Lesser, C.F. and Guthrie, C. 1993. Mutational analysis of premRNA splicing in Saccharomyces cerevisiae using a sensitive new reporter gene, CUP1. Genetics 133: 851-863.

Lin, R.-J., Newman, A.J., Cheng, S.-C., and Abelson, J. 1985. Yeast mRNA splicing in vitro. J. Biol. Chem. 260: 1478014792.

Long, M., Souza, S.D., and Gilbert, W. 1997. The yeast splice site revisited: New exon consensus from genomic analysis. Cell 12: 739-740.
Lopez, P. and Séraphin, B. 1999. Genomic-scale quantitative analysis of yeast pre-mRNA splicing: Implications for splicesite recognition. RNA 5: 1135-1137.

Mayas, R.M., Maita, H., and Staley, J.P. 2006. Exon ligation is proofread by the DExD/H-box ATPase Prp22p. Nat. Struct. Mol. Biol. 13: 482-490.

McGrail, J.C., Tatum, E.M., and O'Keefe, R.T. 2006. Mutation in the U2 snRNA influences exon interactions of U5 snRNA loop 1 during pre-mRNA splicing. EMBO J. 25: 3813-3822.

Newman, A. and Norman, C. 1991. Mutations in yeast U5 snRNA alter the specificity of $5^{\prime}$ splice-site cleavage. Cell 65: 115-123.

Newman, A.J. and Norman, C. 1992. U5 snRNA interacts with exon sequences at $5^{\prime}$ and $3^{\prime}$ splice sites. Cell 68: 743-754.

Newman, A.J., Teigelkamp, S., and Beggs, J.D. 1995. snRNA interactions at $5^{\prime}$ and $3^{\prime}$ splice sites monitored by photoactivated crosslinking in yeast spliceosomes. RNA 1: 968-980.

O'Keefe, R.T. and Newman, A.J. 1998. Functional analysis of the U5 snRNA loop 1 in the second catalytic step of yeast pre-mRNA splicing. EMBO J. 17: 565-574.

O'Keefe, R.T., Norman, C., and Newman, A.J. 1996. The invariant U5 snRNA Loop 1 sequence is dispensable for the first catalytic step of pre-mRNA splicing in yeast. Cell 86: 679689.

Parker, R. and Siliciano, P.G. 1993. Evidence for an essential non-Watson-Crick interaction between the first and last nucleotides of a nuclear pre-mRNA intron. Nature 361: 660662.

Rymond, B. and Rosbash, M. 1985. Cleavage of 5' splice site and lariat formation are independent of $3^{\prime}$ splice site in yeast mRNA splicing. Nature 317: 735-737.

Scadden, A.D.J. and Smith, C.W.J. 1995. Interactions between the terminal bases of mammalian introns are retained in inosine-containing pre-mRNAs. EMBO J. 14: 3236-3246.

Schneider, S., Campodonico, E., and Schwer, B. 2004. Motifs IV and $\mathrm{V}$ in the DEAH box splicing factor Prp22 are important for RNA unwinding, and helicase-defective Prp22 mutants are suppressed by Prp8. J. Biol. Chem. 279: 8617-8626.

Schwer, B. and Gross, C.H. 1998. Prp22, a DExH RNA helicase, plays two distinct roles in yeast pre-mRNA splicing. EMBO J. 17: 2086-2094.

Schwer, B. and Guthrie, C. 1992. A conformational rearrangement in the spliceosome is dependent on PRP16 and ATP hydrolysis. $E M B O J$. 11: 5033-5039.

Siatecka, M., Reyes, J.L., and Konarska, M.M. 1999. Functional interactions of Prp8 with both splice sites at the spliceosomal catalytic center. Genes \& Dev. 13: 1983-1993.

Sontheimer, E.J. and Steitz, J.A. 1993. The U5 and U6 small nuclear RNAs as active site components of the spliceosome. Science 262: 1989-1996.

Spingola, M., Grate, L., Haussler, D., and Ares, M.J. 1999. Genome-wise bioinformatic and molecular analysis of introns in Saccharomyces cerevisiae. RNA 5: 221-234.

Tarn, W.-Y. 1996. Site-specific substitution of inosine at the terminal positions of a pre-mRNA intron: Implications for the configuration of the terminal base interaction. Biochimie 78: 1057-1065.

Teigelkamp, S., Newman, A.J., and Beggs, J.D. 1995. Extensive interactions of PRP8 protein with the $5^{\prime}$ and $3^{\prime}$ splice sites during splicing suggest a role in stabilization of exon alignment by U5 snRNA. EMBO J. 14: 2602-2612.

Turner, I.A., Norman, C.M., Churcher, M.J., and Newman, A.J. 2006. Dissection of Prp8 protein defines multiple interactions with crucial RNA sequences in the catalytic core of the spliceosome. RNA 12: 375-386.

Umen, J.G. and Guthrie, C. 1995. A novel role for a U5 snRNP 
Crotti et al.

protein in $3^{\prime}$ splice site selection. Genes \& Dev. 9: 855-868.

Valadkhan, S. 2005. snRNAs as the catalysts of pre-mRNA splicing. Curr. Opin. Chem. Biol. 9: 603-608.

Will, C.L. and Lührmann, R. 2006. Spliceosome structure and function. In The RNA world (eds. R.F. Gesteland et al.), pp. 369-400. Cold Spring Harbor Laboratory Press, Cold Spring Harbor, NY.

Wyatt, J.R., Sontheimer, E.J., and Steitz, J.A. 1992. Site-specific cross-linking of mammalian U5 snRNP to the $5^{\prime}$ splice site before the first step of pre-mRNA splicing. Genes \& Dev. 6: 2542-2553.

Zhang, X. and Schwer, B. 1997. Functional and physical interaction between the yeast splicing factors Slu7 and Prp18. Nucleic Acids Res. 25: 2146-2152. 


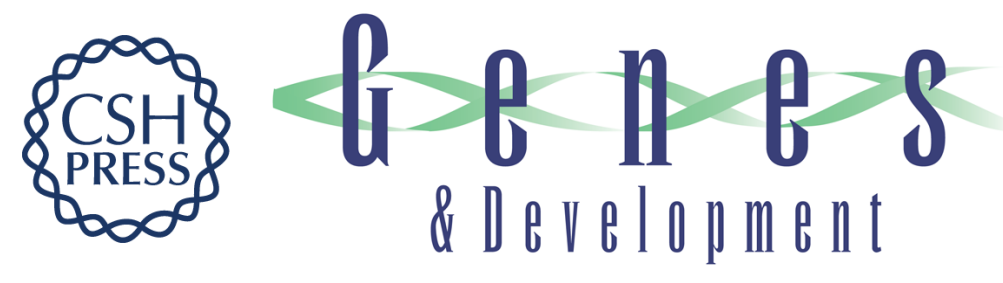

\section{The Prp18 protein stabilizes the interaction of both exons with the U5 snRNA during the second step of pre-mRNA splicing}

Luciana B. Crotti, Dagmar Bacíková and David S. Horowitz

Genes Dev. 2007, 21:

Access the most recent version at doi:10.1101/gad.1538207

Supplemental http://genesdev.cshlp.org/content/suppl/2007/04/30/21.10.1204.DC1
Material

References This article cites 45 articles, 23 of which can be accessed free at:

http://genesdev.cshlp.org/content/21/10/1204.full.html\#ref-list-1

License

Email Alerting

Receive free email alerts when new articles cite this article - sign up in the box at the top

Service

right corner of the article or click here.

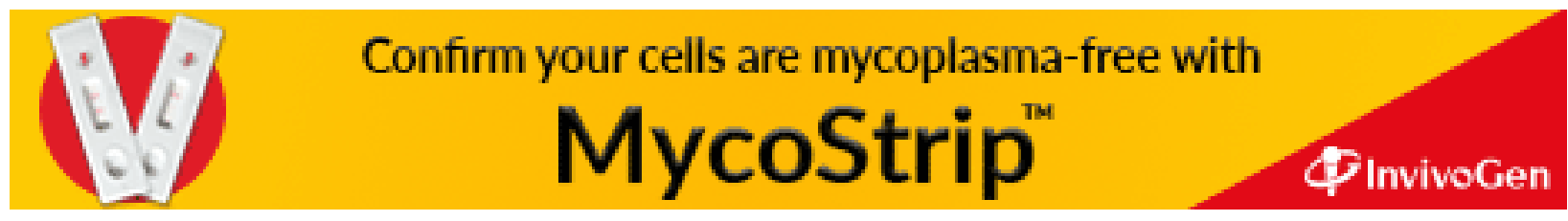

